\title{
BIOPOLÍTICA E NOVAS TECNOLOGIAS: DIREITOS HUMANOS SOB AMEAÇA?
}

\section{BIOPOLITICS AND NEW TECHNOLOGIES: HUMAN RIGHTS UNDER THREAT?}

\author{
MAIQUEL ÂNGELO DEZORDI WERMUTH ${ }^{1}$ \\ VALÉRIA SILVA GALDINO CARDIN ${ }^{2}$ \\ MATHEUS RIBEIRO DE OLIVEIRA WOLOWSKI ${ }^{3}$
}

\begin{abstract}
RESUMO: Diante do avanço das novas tecnologias e o contexto biopolítico contemporâneo de controle social, o artigo se propõe a tecer algumas reflexões sobre eventuais ameaças à direitos humanos e da personalidade, uma vez que o processamento de informações pode fomentar ainda mais o biopoder e o biomercado. Embora cite alguns casos concretos envolvendo a problemática, a pesquisa possui viés teórico e propõe um entrelaçamento entre as teorias de Giorgio Agamben e Fritjof Capra, sobre a necessidade de um pensamento sistêmico para proteger os vulneráveis em um contexto biopolítico de controle social. Ao final, busca-se apontar caminhos para possíveis soluções jurídicas que atenuem prováveis ameaças tecnológicas aos direitos humanos e da personalidade.
\end{abstract}

Palavras-Chave: Biopolítica; Inteligência Artificial; Direitos Humanos; Direitos de Personalidade.

\footnotetext{
${ }^{1}$ Doutor e Mestre em Direito pela Universidade do Vale do Rio dos Sinos (UNISINOS). Especialista em Direito Penal e Direito Processual Penal e Bacharel em Direito pela Universidade Regional do Noroeste do Estado do Rio Grande do Sul (UNIJUÍ). Coordenador do Programa de Pós-Graduação Stricto Sensu em Direito - Mestrado e Doutorado em Direitos Humanos - da UNIJUÍ. Professor do Curso de Graduação em Direito da UNIJUÍ. Pesquisador Gaúcho da Fundação de Amparo à Pesquisa do Estado do Rio Grande do Sul (FAPERGS). Líder do Grupo de Pesquisa Biopolítica e Direitos Humanos, certificado pelo Conselho Nacional de Desenvolvimento Científico e Tecnológico (CNPq).

2 Pós doutora em Direito pela Universidade de Lisboa; Doutora em Direito Civil pela Pontifícia Universidade Católica de São Paulo - SP. Mestra em Direito pela Pontifícia Universidade Católica de São Paulo - SP; Graduada em Direito pela Universidade Estadual de Maringá-PR; Professora associada da Universidade Estadual de Maringá-PR; Professora do programa de mestrado e doutorado da Universidade do Cesumar. Pesquisadora pelo ICETI; Advogada no Paraná

${ }^{3}$ Doutorando em Direito pela Unicesumar - Bolsista PROSUP/CAPES; Aluno especial do Programa de Doutorado em Direito da Unijuí; Mestre em Ciências Jurídicas pela Unicesumar; Graduado em Direito e Teologia pela Unicesumar; Professor universitário e advogado.
} 
ABSTRACT: In view of the advancement of new technologies and the contemporary biopolitical context of social control, the article proposes to make some reflections on possible threats to human rights and personality, since the processing of information can further promote biopower and the biomercado. Although it cites some concrete cases involving the problem, the research has a theoretical bias and proposes an intertwining between the theories of Giorgio Agamben and Fritjof Capra, on the need for a systemic thinking to protect the vulnerable in a biopolitical context of social control. In the end, it seeks to point out ways for possible legal solutions that mitigate probable technological threats to human rights and personality.

KEYWORDs: Biopolitics; Artificial intelligence; Human rights; Personality Rights

\section{INTRODUÇÃO}

O contexto social contemporâneo caracteriza-se pelo consumo exacerbado, muitas vezes induzido por estratégias que agem sobre a dimensão psicológica dos seres humanos a fim de despertá-los para o consumo e, assim, assegurar a manutenção do sistema econômico predominante. Com o avanço das tecnologias e da inteligência artificial, o volume de captação de dados e informações pode potencializar essa questão e, se adentrar ao campo político, haveria possibilidade de instauração de um verdadeiro estado de exceção de corte biopolítico - tal qual desvelado pela filosofia de Giorgio Agamben.

Análises preditivas, big datas, machine learning, são importantes avanços neste contexto de Indústria 4.0. Entretanto, a cautela tem sido evidenciada por conta de eventuais prejuízos a direitos como a intimidade, a privacidade e a honra das pessoas. Além disso, dados passaram a ser compartilhados com agências de marketing político, a fim de aplicar as mesmas técnicas de consumo para angariar votos e restringir as possibilidades de ação daqueles que, eventualmente discordam do modelo de governo.

Sendo assim, busca-se realizar uma abordagem acerca do contexto biopolítico e a eventual ameaça que as tecnologias de informação podem oferecer aos direitos humanos, com a captação e o processamento das informações de comunicação, biométricas e de localização das pessoas.

O presente trabalho assume como marco teórico as premissas de Giorgio Agamben para contextualizar a questão da biopolítica, abordando também, alguns aspectos da necropolítica nos moldes adotados por Sayak Valência. Ademais, para propor caminhos para as soluções dos impasses apresentados, apoia-se nos ideais formulados por Fritjof Capra, propondo uma ideia de trabalho em rede no campo do Direito, em outras palavras, um Direito que opere de forma sistêmica e não mecanizada, tal qual ocorre com a ciência atualmente. 
Destarte, o trabalho se justifica pelo avanço crescente das tecnologias, a ameaça de controle social e violação de direitos humanos, já que a vulnerabilidade das pessoas se torna mais evidente diante das tecnologias. Assim, como forma de preservar os direitos humanos e da personalidade, arduamente conquistados, é imprescindível refletir sobre essas problemáticas a fim de que se encontrem caminhos para solução dessa problemática social extremamente complexa.

Ao final, baseado nas literaturas pesquisadas, o artigo aponta para possíveis soluções que assegurem o desenvolvimento das tecnologias, mas atenuem as eventuais ameaças de controle, de autoritarismo e ameaça aos direitos humanos e da personalidade diante do avanço das novas tecnologias e intensificação da conectividade.

\section{A Biopolítica e A NeCROPOlítica NA CONTEMPORANEIDADE}

No século presente, a sociedade tem vivenciado inúmeras mudanças que conflitam com a importância de normas constitucionais, frente às relações privadas e públicas que seguem um paradigma, ainda, mecanicista, mesmo que a ciência já tenha migrado para uma análise sistêmica ecológica. Fritjof Capra (2018, p. 28) afirma que o paradigma mecanicista

introduz uma ênfase na quantificação, incorporada por Galileu Galilei, e no domínio do homem sobre a natureza, defendido por Francis Bacon; a concepção do mundo material como uma máquina separada da mente, promovida por René Descartes; o conceito newtoniano das "leis da natureza", objetivas e imutáveis; e uma visão racionalista e atomista da sociedade, promovida por John Locke. Já a teoria do direito, o paradigma racionalista e mecanicista, desenvolvido por juristas do século XVII como Hugo Grotius e Jean Domat, vê a realidade como um agregado de componentes distintamente definíveis, proprietários cujos direitos individuais são protegidos pelo Estado.

Ao longo da história o direito sempre acompanhou - ou buscou acompanhar, ainda que de modo retardatário - a ciência, muitas vezes de forma mecânica. Todavia, no contexto contemporâneo a ciência migra para um paradigma sistêmico ecológico, alertando para a necessidade de mudança "da visão do mundo como uma máquina, passa-se a entendê-lo como uma rede." (CAPRA, 2018, p. 29).

Neste mesmo entendimento, no campo jurídico, Otávio Luiz Rodrigues Junior (2011, p. 59), destaca duas consequências contemporâneas deste movimento:

(a) o direito Constitucional foi arrastado para dentro do rodamoinho de disputas privadas de relevância duvidosa, com todos os desagradáveis inconvenientes para si e para a 
Constituição, como o barateamento da dignidade e da importância das normas constitucionais, que se veem citadas em pequenos conflitos individuais, como a cobrança de uma dívida ou a definição dos danos pelo abalroamento de automóveis. Com isso, põe-se a perder a "identidade do direito privado", forjada por sua antiga e respeitável história. (b) a existência de conceitos jurídicos indeterminados e cláusulas gerais na Constituição, o que é esperável dada sua natureza normativa específica, é campo fértil para a ação dos interessados no arbítrio e no abuso da discricionariedade judicial. Se foi possível realizar demagogia judiciária com base em elementos do próprio direito Civil, agora isso é feito com a invocação do texto constitucional.

Diante de crises econômicas, as relações sociais públicas e privadas apelam ao Direito (muitas vezes em nome das normas constitucionais) para prevalecer a visão mecânica de mundo. Com o avanço da tecnologia, diversas empresas têm obtido acesso a dados pessoais de usuários "por razões de segurança", "por conforto" e para "proporcionar uma melhor experiência". Em muitos casos, tais justificativas sequer possuem anuência dos usuários e fomentam a vulnerabilidade do ser humano para o consumo, já que as análises preditivas processam as informações coletadas para despertar nos seres humanos o desejo de consumir.

A título exemplificativo,

a cadeia de lojas Target utilizou análise preditiva em big data para prever quais de suas clientes tinham probabilidade de estar grávidas. (Charles Duhigg, repórter do The New York Times, inicialmente fez a cobertura dessa história.) A Target coletou dados sobre alguns itens específicos que elas compravam, como vitaminas, loções sem cheiro, livros sobre gravidez e roupas de gestante. Usando esses dados, a Target desenvolveu modelos preditivos para gravidez entre suas clientes. Os modelos pontuaram a probabilidade de uma determinada cliente estar grávida. (BARI; CHAOUCHI; JUNG, 2019).

No caso citado, a consumidora soube, através das propagandas que recebia, que estava grávida, antes mesmo de realizar qualquer teste. Valencia conceitua essa prática como Biomercado. Para a autora, seria, “uma categoria epistemológica para decodificar o novo capitalismo em suas demandas e práticas de consumo. Por meio de comportamentos de consumo aparentemente escolhidos, contribuímos para a criação de produtos que ampliam nichos de mercado." (VALENCIA, 2010, p. 151). 
Portanto, questiona-se se haveria limites para uma intervenção tecnológica, já que empresas, governos e grupos detentores de toda essa informação poderão se beneficiar pela vulnerabilidade de muitos seres humanos. Evidentemente, não se pode negar o inevitável avanço trazido pelas novas tecnologias, mas, de igual maneira, não se pode fechar os olhos para possíveis prejuízos aos direitos humanos e da personalidade que poderão ser violados nesse processo.

Diante desse contexto, torna-se necessária a discussão com vias de se apresentar caminhos de alternativa às aflições emergidas pela denominada Revolução 4.0, que com o célere avanço do processamento de dados, inteligência artificial e o machine learning pode tornar o ser humano ainda mais vulnerável pela instrumentalização de arbitrariedades.

Através das tecnologias, a vulnerabilidade humana se torna ainda maior, inclusive diante de governos, uma vez que o processamento de dados pessoais possibilita o aumento do controle social, justificando, "por razões de segurança", políticas autoritárias que limitam direitos humanos e atingem direitos da personalidade, tal qual ocorre com empresas que utilizam dados "por mais segurança" ou outra aparente vantagem.

Esse ideal de justificar políticas ou ações autoritárias e invasivas decorre de uma prática antiga na sociedade, com a indução de pessoas ao medo e ao uso da violência. Nem mesmo com a abolição da escravidão, em contextos como o brasileiro, tal prática foi cessada. Sobre o tema, $\operatorname{Wermuth}(2018$, p. 290) pondera que essa violência foi potencializada, observe-se:

Por meio da violência, as hegemonias conservadoras difundiam o medo de modo a induzir e a justificar políticas autoritárias de controle social, realidade que em nada foi alterada - pelo contrário, foi potenciada - com a abolição da escravidão.

A violência física do passado, na contemporaneidade, tem sido agravada com a violência psíquica de exposição de dados pessoais capazes de compreender todo aspecto psicológico de um indivíduo, através de análises preditivas e comportamentais. Por intermédio do acesso às informações de dados de pesquisas, biométricos e de comportamentos de consumo, emerge-se a preocupação de que, através dos dados pessoais e da inteligência artificial, é possível que haja um controle maior sobre a vida dos seres humanos e sobre a morte, ofendendo-se os direitos humanos arduamente reconhecidos ao longo da história.

No passado, as arbitrariedades decorreram do controle de massas para expansão do autoritarismo e uma espécie de normalização da hostilidade. Como destaca Hannah Arendt (1976, p. 21),

se no estágio final da desintegração os slogans antissemitas constituíam o meio mais eficaz de inspirar grandes massas para 
levá-las à expansão imperialista e à destruição das velhas formas de governo, então a história da relação entre os judeus e o Estado deve conter indicações elementares para entender a hostilidade entre certas camadas da sociedade e os judeus.

Hoje, com o aumento de casos de violência, por exemplo, ações governamentais defendem o uso irrestrito de câmeras de segurança, sem justificar violações aos direitos fundamentais ligados à privacidade, intimidade e imagem. Durante a pandemia da COVID-19, por exemplo, percebeu-se que a gravidade da crise sanitária ensejou inúmeras restrições de liberdade de locomoção, exercício profissional etc., o que se poderia caracterizar como uma evidência de um estado de exceção, cujas razões de segurança suplantam direitos fundamentais e humanos.

Sobre o tema, Giogio Agamben (2007, p. 44) pondera que

o estado de exceção, enquanto figura da necessidade, apresenta-se pois - ao lado da revolução e da instauração de fato de um ordenamento constitucional - como uma medida "ilegal", mas perfeitamente "jurídica e constitucional", que se concretiza na criação de novas normas (ou de uma nova ordem jurídica).

Portanto, partindo dessa premissa, em certa medida, tais políticas restritivas são facilmente aceitas pelas grandes massas e o controle social passa a se intensificar de forma sorrateira, configurando-se um estado de exceção contemporâneo através da transformação da vida no centro da política. Neste sentido, "o conceito de biopolítica nomeia, de modo geral, as relações de poder que envolvem a vida biológica, indicando a indiferenciação entre a vida do homem como ser vivo e a vida política, conforme a clássica distinção aristotélica." (SOUZA, 2017, p.16). Essas transformações da sociedade são perspectivadas por Agamben a partir da análise desenvolvida pioneiramente por Michel Foucault.

Alvarez (2004, p. 174) explica, de forma objetiva que,

para Agamben, o que caracteriza o poder soberano no Ocidente é a politização crescente da "vida nua", da vida natural ou biológica tanto do corpo individual quanto da própria espécie. O poder estatal dirige-se cada vez mais ao gerenciamento da vida em todos os seus aspectos, intensificando assim seu aspecto "produtivo", já enfatizado anteriormente por Foucault.

A ótica de Agamben traz a reflexão quanto à atuação moderna de controle das vidas para manutenção do poder, sobretudo daquelas que se caracterizam como possível ameaça ao poder soberano. Destarte, administrar o modo de vida das populações é fundamental para manter-se no poder e os instrumentos utilizados, 
muitas vezes, decorrem de atos que, a princípio, são aceitáveis pela grande massa com serenidade e legalidade.

Neste contexto, é importante destacar que

a presença da vontade soberana na sombra da ordem social coloca a vida humana, todas as vidas humanas, sobre a potencial ameaça da exceção. Isso quer dizer que, se por qualquer circunstância, uma pessoa ou um grupo populacional representasse para ordem uma ameaça real ou suposta, eles poderão sofrer a suspensão parcial ou total dos direitos para melhor controle de suas vidas (RUIZ, 2012, p.5)

Portanto, aqueles que eventualmente figurarem como ameaça terão suas vidas administradas através de cerceamentos de direitos de liberdade, privacidade, expressão e outros direitos fundamentais e humanos, mediante a imposição de políticas totalitárias com respaldo jurídico e aceitável pela grande massa. Essa questão suscitada por Agamben pode se agravar diante da quantidade de dados interligados pelos novos meios tecnológicos, denominados de big data. Essa terminologia decorre da conceituação advinda de grandes servidores informáticos que armazenam exacerbado volume de dados, produzindo informações que podem facilitar ainda mais o controle sobre as vidas, já que se é possível prever o comportamento de seres humanos e, assim, agravar o gerenciamento sobre a vida.

Outra terminologia que se torna pertinente nesta discussão consiste na necropolítica. Sayak Valencia, ao empreender essa abordagem, afirma que,

se a biopolítica é entendida como a arte de administrar o viver das populações, as demandas capitalistas têm feito viver e todos os seus processos associados tornam-se mercadorias o que pode ser equiparado ao que entendemos por necropoder, uma vez que este representa a gestão do último e mais radical dos processos de viver: a morte. (VALENCIA, 2010, p.142)

Em seus textos, Valencia (2010) pondera que existe um interesse de lucro que decorre da violência e morte das pessoas, citando, dentre outros exemplos, a cidade mexicana de Tijuana, que tem se tornado uma espécie de "Narco-nação", já que as forças de segurança não conseguem fazer valer a lei e acabam cooperando com a cultura criminal, já que não encontram outra saída para o problema. Ainda sobre esse ponto, a autora relata que

no caso do México poderíamos dizer que a explosão do Estadonação ocorreu de forma sui generis posto que o novo estado não é ostentado pelo governo, mas sim pelo crime organizado, 
principalmente pelos cartéis de drogas, que integra o cumprimento literal das lógicas mercantis e a violência como ferramenta de empoderamento, tornando-se assim um 'Narco-Nação'. (VALENCIA, 2010, p. 34).

Desta forma, para a autora, o governo mexicano se torna conivente com a violência resultada pelo narcotráfico, não buscando inibi-lo, mas limitando-o e utilizando-o em benefício próprio (VALENCIA, 2010, p. 38). Certamente, tal premissa emergida pela autora causa preocupação com a possibilidade desse controle se tornar ainda mais potente com o avanço de tecnologias que processam dados, realizam análises preditivas ou então utilizam-se de inteligência artificial para a obtenção de vantagens em detrimento das camadas mais vulneráveis e ofensa aos direitos humanos e da personalidade.

Direitos como a privacidade, a honra, a intimidade, a saúde (física e psíquica) e até mesmo a vida podem ser potencialmente desrespeitados diante de práticas advindas da biopolítica e da necropolítica. Não bastando o prejuízo ao ser humano de tais práticas, emerge-se preocupação mais elevada diante dos avanços tecnológicos que poderão fomentar ainda mais as arbitrariedades aos vulneráveis. Importante, ainda, ressaltar que, no campo das tecnologias, todos, de uma forma ou de outra, acabam se tornando vulneráveis.

Logo, resta evidente que os avanços tecnológicos, por conta do seu intenso e necessário processamento de dados pessoais para configuração de Machine Learning e análises preditivas, apresentam-se como risco de controle social e consequente violação aos direitos humanos se aplicadas às práticas de biopolítica/necropoder. Assim, torna-se importante compreender o avanço dessas tecnologias e estabelecer balizas que assegurem o desenvolvimento tecnológico, sem ofender os direitos humanos e dar azo às arbitrariedades na contemporaneidade.

\section{O AVANÇO DA INTELIGÊNCIA ARTIFICIAL E A (IM)POSSIBILIDADE DE LESÃO AOS DIREITOS HUMANOS E CONSOLIDAÇÃO DO AUTORITARISMO}

Lesões aos direitos da personalidade são cada vez mais frequentes neste contexto tecnológico. Os denominados cibercrimes são cada vez mais comuns e praticados pelas redes sociais através de Cyberbullying ${ }^{4}$ e do Revenge Porn ${ }^{5}$, discursos

${ }^{4} \mathrm{O}$ cyberbullying vem sendo definido pelo recurso às tecnologias da comunicação e informação para deturpar, humilhar e/ou difamar uma ou mais pessoas. (PINHEIRO, 2009, p.29)

${ }^{5}$ No Brasil, não há uma definição específica para o termo "Revenge Porn", sendo então chamado de Pornô Vingativo, Pornô de Vingança, Pornografia de Vingança ou Vingança Pornográfica. Independente do termo utilizado, essa conduta trata-se de uma violência de gênero. (ALMEIDA, et al, 2020, p.1801). Entretanto, o art. 218-C do Código Penal tipificou essa prática como crime: Art. 218-C. Oferecer, trocar, disponibilizar, transmitir, vender ou expor à venda, distribuir, publicar ou divulgar, por qualquer meio - inclusive por meio de comunicação de massa ou sistema de informática ou telemática -, fotografia, vídeo ou outro registro audiovisual que contenha cena de estupro ou de estupro de vulnerável ou que faça apologia ou induza a sua prática, ou, sem o 
que incitam violência e outras ameaças de exposição de informações para fins de chantagens e extorsão.

Uma série televisiva da Netflix, denominada Black Mirror, apresentou de forma clara a preocupação com eventuais atos de exposição de dados ou informações para manipulação e controle sobre vidas, no episódio "Manda quem pode" de sua terceira temporada. Em resumo, esse episódio narra a história de um jovem que teve seu computador invadido e precisa decidir se obedece aos hackers ou se tem sua intimidade exposta para sua família.

Embora a famigerada série televisiva tenha algumas temporadas e episódios surreais, esse em específico já se mostra plenamente possível de acontecer, basta relembrar o recente "Desafio da baleia azul" ${ }^{6}$, que levou inúmeros adolescentes a cometerem lesões corporais e até mesmo suicídio. Embora não exista diretamente a ameaça de exposição de dados nesse desafio, muitos jovens cometeram suicídio e isso, certamente, se agravaria se houvesse a possibilidade de uma eventual divulgação de informação que viole a intimidade ou privacidade do indivíduo.

Se, com as redes sociais, a incidência de crimes e possibilidades de exposição são maiores, o uso da inteligência artificial e sistemas que processam os dados obtidos pelo uso constante das tecnologias pode agravar ainda mais as ofensas aos direitos da personalidade como honra, imagem e intimidade. Além disso, ainda que não sejam expostos os dados coletados, grandes grupos econômicos, políticos e sociais, podem tratar esses dados para obter vantagens de lucro e/ou poder, sem que as pessoas tenham consentimento de uma possível manipulação.

Antes de adentrar no debate acerca de eventuais lesões aos direitos humanos, da personalidade e eventual fomento ao totalitarismo, por conta do avanço das novas tecnologias de inteligência artificial, torna-se de bom alvitre resgatar alguns conceitos para então aprofundar a discussão.

Iniciando pelo conceito de Inteligência Artificial, segundo a Comissão Europeia de Inteligência Artificial, tratam-se de sistemas que demonstram um comportamento inteligente: a análise de seu entorno permite que eles realizem diversas tarefas com certo grau de autonomia para alcançar objetivos específicos. (EUROPEAN COMISSION, 2018, p.2). Dentre as tarefas que a inteligência artificial pode desenvolver, destaca-se a análise preditiva, já ventilada no capítulo anterior deste artigo. Algumas das tecnologias de inteligência artificial não desenvolvem apenas tarefas automatizadas, mas possuem certa independência e autonomia, por conta de algoritmos Machine Learning (Aprendizado máquina), o que impossibilita qualquer previsão acerca dos limites de atuação dessa análise preditiva.

consentimento da vítima, cena de sexo, nudez ou pornografia: Pena - reclusão, de 1 (um) a 5 (cinco) anos, se o fato não constitui crime mais grave.

${ }^{6} \mathrm{O}$ jogo estabelece 50 desafios por dia que culminam com o suicídio do participante. Segundo as investigações abertas pela Delegacia de Repressão a Crimes de Informática do Rio, é importante a figura do curador, protegido por um perfil falso na rede social. Ele apadrinha, guia e fiscaliza o novo membro durante o macabro jogo. (BEDINELLI, 2017) 
Basicamente, o Machine Learning, consiste na tecnologia em que a máquina pratica algo de forma constante e reiterada, a ponto de desenvolver atividades de forma independente, sem que, muitas vezes, o criador consiga prever eventuais ações e tomadas de decisão. Empresas como Uber e Tesla, por exemplo, já desenvolveram veículos autônomos com essa tecnologia. Na China, houve liberação de cinco mil caminhões autônomos, fabricados pela empresa TuSimple, que rodaram cerca de quarenta e cinco mil $\mathrm{km}$ sem qualquer acidente grave (ZMOGINSKI, 2021). Evidente, portanto, que esse avanço tecnológico é inevitável e importante para a sociedade. Contudo, a tomada de decisão dessas máquinas se pauta em valores éticos imprevisíveis e, eventualmente, podem causar danos ao ser humano, a depender das circunstâncias concretas.

Do mesmo modo que essas máquinas desenvolvidas para o transporte autônomo, existem softwares e outras dispositivos que desenvolvem atividades de forma autônoma através do Machine Learning. As possibilidades de atuação são ilimitadas. Existem componentes capazes de jogar partidas de xadrez, desenvolver argumentações, discursos, minutas de contratos, sentenças e tantas outras atividades que até então eram reservadas aos seres humanos. Sobre esse ponto, pesquisas realizam algumas considerações sobre tais possibilidades, destacando a importância da conectividade:

A expansão das tecnologias, que viabilizam esses novos serviços de internet, leva a mudanças na maneira como as pessoas e as organizações interagem (LLOYD; FULLAGA; REID, 2016), dando origem a ambiguidades legais e problemas legais originais. Essas tecnologias incluem computação em nuvem, big data, Internet das Coisas (IoT), inteligência artificial (AI), criptografia, sensores, robôs, algoritmos e outros sistemas relacionados à informação. A maioria dessas tecnologias depende de infraestruturas de computação em nuvem para operar no nível superior. Um conceito específico conhecido como IoT é o principal facilitador para a conectividade de dispositivos de computação. A Internet das Coisas abraça um novo conceito pelo qual o mundo virtual da Internet converge com o mundo cotidiano das "coisas". A ideia é conectar pessoas entre si, mas também pessoas com organizações e itens do dia a dia. (SOARES; KAUFFMAN; CHAO; SAAD, 2020, p.3, tradução livre)

Partindo dessas premissas, importante retomar a discussão acerca da relação existente entre a inteligência artificial e a eventual ameaça aos direitos humanos e estados totalitários. Fator fundamental para o desenvolvimento dessas tecnologias consiste na questão da conectividade através da internet. Como visto, grande parte 
das infraestruturas de computação necessitam de dados em nuvem para processar as informações e desenvolverem suas atividades.

Os seres humanos têm estado constantemente conectados a dispositivos informáticos e inúmeras informações são processadas diariamente, como conversas, compras, acessos, pesquisas, dados biométricos, locomoção e uma infinidade de outras situações. Observando de forma simples, aparentemente, nada há de errado com isso, já que as informações são processadas para o efetivo funcionamento desses dispositivos.

Contudo, as informações armazenadas podem ser objeto de utilização para uma gestão de vida ou até mesmo da morte e consolidar estados totalitários, vulnerando assim direitos humanos e da personalidade. E de que forma poderia, a tecnologia, ser um instrumento para consolidação do totalitarismo e ofensa aos direitos humanos e da personalidade?

Em 2006, o matemático Clive Humby mencionou a frase: "Data is a new oil" (HUMBY, 2006, p.2), que traduzida significa, "Dados são o novo petróleo". Essa menção reflete a imensa importância que os dados dos seres humanos possuem para o sistema econômico contemporâneo e, com o avanço da inteligência artificial, a captação desses dados, somada à capacidade de processamento, pode contribuir para entender, em um regime de biopoder, quais são as eventuais ameaças ao soberano e que medidas poderão ser tomadas para manutenção do poder.

Esses dados também são costumeiramente utilizados no campo do consumo por empresas que buscam aumentar os seus lucros, através da exploração dessas informações, ofertando aquilo que o consumidor deseja adquirir, ainda que não precise. Logo, tais dados são de suma importância para a indústria de consumo, para grupos políticos, religiosos e outras tendências sociais que necessitem entender o comportamento da sociedade para obter alguma vantagem, seja de lucro ou de controle.

Segundo o executivo da empresa Locaweb,

pode-se dizer que o big data é a essência desse fenômeno. Chegamos até aqui para colher o ouro das informações geradas por meio da interação com as máquinas. Agora temos que nos esforçar para interpretar o que os dados têm a nos dizer. Todo investimento em Inteligência de dados é de extrema importância, porque a revolução 4.0 é justamente essa: nunca tivemos tão perto de saber tanto o que produzimos e sobre o que vendemos. (GLIKAS, 2018)

Nesse contexto, torna-se clara a preocupação com eventuais prejuízos causados pela proteção desses dados armazenados em big datas, tanto que diversos países estão legislando sobre proteção de dados. O Brasil aprovou a Lei n. 13.709/2018 no intuito de atenuar eventuais ofensas à direitos como privacidade e intimidade, mas ainda assim, fica o questionamento da possibilidade de processamento desses 
dados para uma biopolítica e uma ameaça totalitarista na contemporaneidade. Seria essa legislação suficiente para resguardar os direitos humanos?

Conforme ressalta Diniz (2018),

sempre houve suspeita de que esses dados poderiam ser utilizados de forma indevida. Essa suspeita ganhou contornos mais reais quando se descobriu que houve um vazamento de dados de 87 milhões de usuários do Facebook para a empresa de marketing político Cambridge Analytica, que atuou na campanha eleitoral de Donald Trump. No Brasil, foram vazados os dados de 443 mil pessoas.

Diante desses fatos, por mais que seja louvável uma legislação de proteção de dados, a questão da efetividade é muito questionada, já que agências reguladoras poderão ter acesso aos dados de inúmeras pessoas e países e trabalhar em paralelo à legislação, sem sofrer com qualquer punição ou possibilidade de reparação de danos. Perceba-se que o Facebook, mesmo com o vazamento de dados de mais de 87 milhões de indivíduos, não reparou os danos causados a essas pessoas e segue tendo faturamentos expressivos.

Tomasevicius Filho (2018, p. 146) pondera que,

com o controle de enorme quantidade de dados sobre as pessoas e a possibilidade de conhecê-las com precisão, tem-se hipótese de subversão da ética no uso da tecnologia: em vez de servir à humanidade, servirá para controlá-la. Em suma, a inteligência artificial não é um mal em si mesma. O mal está no mau uso que alguém pode fazer dela. Impõe-se, portanto, o dever de exigir que seja usada exclusivamente em favor da humanidade, jamais com o intuito de promover o controle social e o fim das liberdades.

O ponto suscitado pelo autor supramencionado é justamente o que carece de solução nos tempos atuais, pois quais seriam os aspectos que levariam a tecnologia a não mais servir o homem e sim de promover o controle social e o fim das liberdades? Ou, ainda, seduzir a população para um consumo desequilibrado? Questões complexas como essas necessitam ser refletidas, já que claramente se apresenta a importância da inteligência artificial no contexto contemporâneo, mas também a irrefutável ameaça aos direitos humanos e da personalidade, quando essas tecnologias podem ser utilizadas para o controle social e violação de direitos. 


\section{Proteção aOs VUlneráveis e o DesenVolvimento EQUilibrado das TECNOLOGIAS NA CONTEMPORANEIDADE}

Quando se fala em vulneráveis no campo jurídico, importante estabelecer uma distinção conceitual existente entre minorias e grupos vulneráveis. As minorias podem ser compreendidas como aqueles que possuem

traço cultural comum presente em todos os indivíduos, originando grupos específicos, são sujeitos ligados entre si, daí a denominação "minoria" [como especificação]. Entretanto, nem sempre diz respeito a um grupo que possui o menor número de pessoas, pelo contrário, por vezes são numerosos. A exemplo, indígenas, homossexuais, negros, crianças, idosos. (SIQUEIRA; CASTRO, 2017, p. 110-111).

Já os grupos vulneráveis são aqueles em que

não há uma identidade, um traço em comum entre os indivíduos como fator que os atraem; são grupos compostos pela sociedade de uma maneira geral. A exemplo, consumidores, litigantes, sindicatos, deficientes, o acusado penal. Compreende-se que são indivíduos suscetíveis de ser feridos, ofendidos ou atacados. (AMORA, 2009, p. 778).

Compreendida tal distinção, é importante considerar que, em se tratando de tecnologias, não apenas os grupos tradicionalmente vistos como vulneráveis, como idosos, analfabetos, consumidores etc. que se encontram vulneráveis a esse controle de dados, mas a grande maioria da população humana enquadra-se, hoje, nesse grupo. $\mathrm{O}$ contato do ser humano com a tecnologia, desde os tempos de assunção da televisão, já passaram a torná-lo vulnerável.

Segundo Kerckhove (2009, p. 32),

quando vemos TV são os elétrons explorando a superfície do cinescópio que nos "lêem". As nossas retinas são o objeto direto do feixe de elétrons. Quando essa exploração se cruza com o olhar e estabelece contato visual entre homem e máquina, o olhar da máquina é mais poderoso. Em frente à tela da televisão as nossas defesas estão em baixa; somos vulneráveis e suscetíveis à sedução multissensorial.

No mesmo sentido, Rezende (2012, p. 18) afirma que "estamos imersos em um processo civilizatório em que as imagens exercem um poder imenso sobre nossas mentes e nossos corpos." Portanto, se os seres humanos se tornam vulneráveis em 
frente a uma tela de televisão, quanto mais fornecendo todos os seus dados às empresas e governos que os exploram cada vez mais.

João Areosa (2015), explorou um interessante trabalho publicado na Revista Angolana de Ciências Sociais, sobre as preocupações com os males das tecnologias. Em seu trabalho, o autor deixa clara a impressão de que, muitas vezes, a população tem se tornado um experimento social das tecnologias, o que pode resultar em consequências imprevisíveis, uma vez que todas as tecnologias estão suscetíveis a acidentes. Segundo ele,

não existem organizações isentas de risco, logo, os acidentes são eventos inevitáveis e passíveis de ocorrer a qualquer momento. Porém, isto não significa que a prevenção não seja útil, mas é pertinente considerar que até a «melhor» estratégia de prevenção tem os seus limites. (AREOSA, 2015, p. 42).

Contudo, essa questão de acidentes carece de uma análise para saber se haveria um tratamento de dados culposo ou doloso para fins de instaurar um controle social e limitar direitos, já que, diante da tecnologia, todo ser humano é vulnerável, sobretudo quando seus dados estão armazenados em Big datas.

Casos no passado, como os já citados neste trabalho, envolvendo a varejista Target e o vazamento de dados de 87 milhões de pessoas pelo Facebook à empresa de marketing político demonstram um retrospecto desses "acidentes". Contudo, o que mais pode tornar o ser humano vulnerável consiste no contexto político em utilizar-se de tais tecnologias para o controle social e, para coibir isso, as experiências do passado não contribuem de forma significativa.

Areosa (2015, p. 43) aponta que,

mesmo a experiência de acidentes anteriores pouco pode acrescentar à prevenção de futuros acidentes, visto que $o$ alinhamento das suas causas e circunstâncias é normalmente singular ou quase irrepetível. Sem dúvida que as tecnologias nos oferecem normalmente um lado benéfico e outro prejudicial (julgamos que este aspecto é relativamente consensual). Aquilo que se torna complexo e problemático no debate sobre algumas tecnologias é a decisão política de aceitá-las ou rejeitá-las.

Destarte, não deve ser admitida uma decisão política de negar ou rejeitar tal realidade, pois trata-se de um problema que precisa ser debatido de forma coletiva e global, uma vez que as tecnologias estão interligadas e o processo de produção dos equipamentos são realizados em um contexto multinacional. Nesse quadro, a transparência é algo que necessita ser assegurado. Ademais, capacitar as pessoas e assegurar a voluntariedade de não depender de tais recursos é algo importante 
para proteção dos direitos humanos e garantia de imiscuir-se de qualquer espécie de controle social por esses mecanismos.

Sobre esse aspecto, Bonaldo e Cugini (2020, p. 43) destacam:

1) o princípio segundo o qual o controle humano deve ser necessário, sempre e em qualquer caso, uma vez que os sistemas de inteligência artificial devem ser concebidos como adequados para apoiar a autonomia humana e a tomada de decisões, de acordo com o princípio de respeito pela autonomia humana;

2) a robustez, confiabilidade e segurança inerentes a cada algoritmo, de modo a superar facilmente obstáculos, erros ou inconsistências que possam ter ocorrido durante a vida dos sistemas de inteligência artificial.

É imprescindível que big datas e os dispositivos de inteligência artificial comprovem a inequívoca confiabilidade e respeito a autonomia humana, desde a tomada de decisões e o respeito aos direitos humanos e individuais. No parlamento brasileiro, tramita o Projeto de Lei no 5691 de 2019, com o intuito de estabelecer a Política Nacional de Inteligência Artificial. Do referido projeto de lei se extrai que

são princípios da Política Nacional de Inteligência Artificial: I desenvolvimento inclusivo e sustentável; II -respeito a ética, aos direitos humanos, aos valores democráticos e à diversidade; III proteção da privacidade e dos dados pessoais; IV -transparência, segurança e confiabilidade. (BRASIL, 2019, p.2)

Contudo, torna-se necessário um debate mais aprofundado para esmiuçar cada palavra desses princípios, de modo a evitar que a biopolítica seja instaurada como estado de exceção e se sucumba com o biomercado, assegurando a proteção aos vulneráveis (que neste caso sempre serão os seres humanos, já que carecem de expertise tecnológica).

A Unesco, em 15 de maio de 2020, elaborou um esboço de recomendações éticas para o desenvolvimento da inteligência artificial, apontando para a necessidade de uma legislação internacional padronizada:

Os governos devem desempenhar um papel de liderança na garantia da segurança e proteção dos sistemas de IA inclusive estabelecendo padrões nacionais e internacionais consistentes com as leis, padrões e princípios internacionais aplicáveis de direitos humanos. A pesquisa estratégica sobre os riscos potenciais de segurança e proteção associados a diferentes abordagens para tornar a IA eficaz a longo prazo deve ser constantemente apoiada 
para evitar danos catastróficos. - Tradução nossa - (UNESCO, 2020, p. 11)

Considerando que a economia é totalmente globalizada e o compartilhamento de tecnologia é cotidiano, torna-se importante a criação de normas que regulamentem o processo produtivo de mecanismos dotados e inteligência artificial e que utilizam big data. Contudo, ainda mais importe é assegurar fiscalização e punição para qualquer empresa ou governo que utilize, de maneira ilegal, as tecnologias para ofender direitos humanos e da personalidade, como a privacidade, intimidade, honra e autonomia.

Quanto à preocupação de tutela dos direitos da personalidade, Wolowski e Cardin (2020, p. 57), asseveram:

No tocante a relação com os direitos de personalidade, importante se observar as diretrizes dos países europeus e também defendidas nos Estados Unidos, resguardando a transparência e auditorias em dispositivos que envolvam Inteligência Artificial, observando-se os impactos sociais a fim de propor mecanismos para atuar os efeitos da expansão da Inteligência Artificial no ambiente de trabalho, no trato com a privacidade dos seres humanos e na segurança quanto ao armazenamento das informações personalíssimas.

Portanto, já existe certa preocupação em positivar algumas diretrizes, contudo se acredita que, embora louvável, essa ação por si só carece de efetividade, já que não é assegurada a possibilidade de coibir eventuais lesões aos direitos da personalidade, bem como manter o estado democrático livre de ameaças autoritárias e de controle social sobre a vida nua. ${ }^{7}$

A questão carece de um debate mais amplo e multidisciplinar, envolvendo diversas áreas do conhecimento para que se alcance um denominador sistêmico e a ciência trabalhe em rede (CAPRA, 2018, p. 29) para os processos de transparência e garantia da soberania humana e das democracias sejam efetivos. Em uma economia globalizada, as questões de funcionamento, transparência segurança e

\footnotetext{
${ }^{7}$ Complementando as investigações de Michel Foucault e de Hanna Arendt, Giogio Agamben emprega o termo "vida nua" para evidenciar o substrato originário do poder. Nas palavras do autor, "aquilo que chamo vida nua é uma produção específica do poder e não um dado natural. Enquanto nos movimentarmos no espaço e retrocedermos no tempo, jamais encontraremos - nem sequer nas condições mais primitivas - um homem sem linguagem e sem cultura. Nem sequer a criança é vida nua: ao contrário, vive em uma espécie de corte bizantina na qual cada ato está sempre já revestido de suas formas cerimoniais. Podemos, por outro lado, produzir artificialmente condições nas quais algo assim como uma vida nua se separa de seu contexto: o muçulmano em Auschwitz, a pessoa em estado de coma etc." (AGAMBEN, 2006b: 135).
} 
punição para desvirtuamento do uso tecnológico devem ser claros e efetivos, já que o acesso e processamento das informações possuem excessivo valor na contemporaneidade.

Em um contexto de sistema jurídico mecanizado, isto é, em que cada país possui suas regras de conduta, será inviável para proteção dos direitos humanos e de personalidade qualquer legislação, já que alguns países poderão não cumprir com as referidas normas, não sofrer punições e manter um estado de exceção, controlando a vida nua de pessoas que alimentam os grandes bancos de dados.

Não se defende o retrocesso das tecnologias, muito pelo contrário. Acredita-se que o avanço tecnológico é importante para sociedade e deve seguir avançando. Entretanto, o desenvolvimento deve ser equilibrado com a proteção da soberania humana, autonomia psíquica, tutela dos direitos humanos e da personalidade, bem como a proteção à ordem democrática, de modo que as informações processadas não sirvam de controle sobre a vida nua, ou como intimidações para realização de determinadas tarefas a contragosto.

Só se conseguirá uma legislação que protegerá a sociedade dessas ameaças quando os legisladores deixarem o modelo mecanicista do direito e seguirem de forma sistêmica, trabalhando em redes, com o apoio de diversas áreas do conhecimento. A ciência já evoluiu e tem trabalhado dessa forma (inclusive para desenvolver os dispositivos de inteligência artificial). Assim também deve ocorrer com o direito e o sistema político. Contudo, a grande massa precisa acordar para trabalhar de forma coletiva e evitar qualquer controle biopolítico ou de biomercado, preservando assim, os direitos humanos arduamente conquistados ao longo da história.

\section{CONCLUSÃO}

O legado do pensamento de Lefebvre sobre a sociedade burocrática de consumo dir Na contemporaneidade, direitos como a privacidade, a intimidade, liberdade e honra, sucumbem cada vez mais diante de medidas autoritárias que visam a justificar determinadas "razões de segurança" em prol da proteção à vida nua. Com o advento das tecnologias, as informações tornaram-se mais vulneráveis, o que facilita o controle biopolítico sobre a grande massa e também sobre eventuais opositores. No campo do consumo essa sistemática também pode ser aplicada ao biomercado, já que com o processamento de dados, a indústria consegue compreender os anseios das pessoas e incentivar o consumo, muitas vezes desnecessários.

A necropolítica também consiste em um fato social que pode ser fomentado com o aumento das tecnologias, uma vez que o Estado (como o relato mexicano) tornase conivente com a criminalidade e lucra com isso. Logo, o aumento da captação e processamento de informações auxilia ainda mais a manutenção dessa sistemática que ofende frontalmente o direito à vida, segurança, saúde e outros que são reconhecidos constitucionalmente. 
O avanço tecnológico possui grande relevância e importância para o ser humano, mas é necessário ter cautela com a utilização, proteção e segurança de dados, garantindo que a máquina sirva o ser humano em sua coletividade, a autonomia individual e o estado democrático de direito.

Além disso, as normas jurídicas carecem de uma participação globalizada e multidisciplinar para que a regulação seja desenvolvida de forma sistêmica e equilibrada, com regras rígidas e efetivas sanção para aqueles que ofenderem direitos humanos para o estabelecimento de estado de exceção e manipulação da grande massa.

A busca pela efetividade da lei, preliminarmente, pode aparentar certa utopia diante da dificuldade da mudança de mentalidade mecanicista para algo sistêmico. Contudo, a ciência já migrou para essa ótica de um trabalho em rede e sustentável e é necessário que a população e os sistemas jurídicos se adequem a essa nova realidade.

A cada dia, as circunstâncias demonstram que a necessidade para sobrevivência é coletiva e isso se torna claro no aspecto ambiental, econômico e político. Portanto, é necessário que a academia e sociedade civil se conscientizem das problemáticas e busquem, de forma conjunta, regulamentar e efetivar normas que assegurem a sobrevivência humana e para isso, os direitos humanos e da personalidade devem ser preservados, já que até mesmos os detentores do poder não resistiram se algo não for feito. Diante das tecnologias, todos são vulneráveis e precisam trabalhar em conjunto.

\section{REFERÊNCIAS}

AGAMBEN, Giorgio. COSTA, Flávia. Entrevista com Giorgio Agamben. Revista do Departamento de Psicologia -UFF, Niterói, v. 18, n. 1, p. 131-136, jun. 2006.

AGAMBEN, Giorgio. Homo Sacer: o poder soberano e a vida nua. Belo Horizonte: Editora UFMG, 2007.

ALMEIDA, Rariel Torres de; ALMEIDA, Marinalva Severina; CARVALHO, Adriana Pereira Dantas. $A$ relevância da lei 13.718/2018, seus impactos nos casos de revenge porn e a preservação ao princípio da dignidade da pessoa humana. Disponível em: https://www.cidp.pt/revistas/rjlb/2020/5/2020_05_1807_1834.pdf Acesso em: 01 de fev. 2021.

ALVAREZ, Marcos César. Controle social: notas em torno de uma noção polêmica. São Paulo em perspectiva, v. 18, n. 1, p. 168-176, 2004.

AMORA, Antônio Soares. Minidicionário da língua portuguesa. 19. ed. São Paulo: Saraiva, 2009. 
ARENDT, Hannah. As origens do totalitarismo. Rio de Janeiro: Documentário, 1976.

AREOSA, João. Riscos sociais, tecnologias e acidentes. Mulemba. Revista Angolana de Ciências Sociais, n. 5 (9), p. 19-53, 2015.

BARI, Anasse; CHAOUCHI, Mohamed; JUNG, Tommy. Análise Preditiva para leigos. Rio de Janeiro: Alta Books, 2019.

BEDINELLI, Talita. Baleia Azul: o misterioso jogo que escancarou o tabu do suicídio juvenil. Disponível em:

https://brasil.elpais.com/brasil/2017/04/27/politica/1493305523_711865.html Acesso em: 30 de janeiro de 2021.

BONALDO, Arianna; CUGINI, Gianvirgilio. Intelligenza artificiale: responsabilità nella progettazione e utilizzo di sistemi Analisi della tematica e riflessi legali,

fiscali ed etici. In: Diritto tributario internazionale e dell'EU, Jan. p. 39-44, 2020.

BRASIL. Senado Federal. Projeto de Lei no 5691, de 2019 -Estabelece princípios para o uso da Inteligência Artificial no Brasil. Senador Styvenson Valentim (PODEMOS/RN). Disponível em: https://legis.senado.leg.br/sdleggetter/documento?dm=8031122\&ts=1582300641960\&disposition=inline Acesso em: 28 jan. 2021.

CAPRA, Fritjof. A revolução ecojurídica: o direito sistêmico em sintonia com a natureza e a comunidade. São Paulo: Editora Cultrix, 2018.

DINIZ, Paulo. Palavra do presidente. A lei geral de proteção de dados pessoais. SINAT. Disponível em: https://www.sinat.com.br/ilionnet/informativolayout.sp?id=44121 Acesso em: 30 de janeiro de 2021 .

EUROPEAN COMISSION. Communication Artificial Intelligence for Europe, 2018. Disponível em: https://ec.europa.eu/digital-singlemarket/en/news/communication-artificial-intelligence-europe Acesso em: 05 jan. 2021.

GLIKAS, Alexandre. Indústria 4.0: empresas são desafiadas a aproveitar o "novo petróleo", 2018. Disponível em:

$<$ https://computerworld.com.br/2018/12/02/industria-4-0-empresas-saodesafiadas-a-aproveitar-novo-petroleo/> Acesso em: 30 de janeiro de 2021. 
HUMBY, Clive. Data is the new oil. Proc. ANA Sr. Marketer's Summit. Evanston, IL, USA, 2006.

KERCKHOVE, Derrick. A pele da cultura: investigando a nova realidade eletrônica. São Paulo: Annablume, 2009.

PINHEIRO, Luzia. Cyberbullying em Portugal: uma perspectiva sociológica. 2009. Tese de Doutorado. Universidade do Minho. Disponível em: https://repositorium.sdum.uminho.pt/bitstream/1822/9870/1/tese.pdf Acesso em: 08 de março de 2021.

REZENDE, Renata. 1. A tecnologia e a transformação do dispositivo televisivo: produções sensórias no hibridismo realidade/ficção. Revista brasileira de história da mídia, v. 1, n. 2, 2012.

RODRIGUES JUNIOR., Otávio Luiz. Direito civil contemporâneo: estatuto epistemológico, constituição e direitos fundamentais. Rio de Janeiro: Forense Universitária, 2019.

RUIZ, Castor M. M. Bartolomé. A sacralidade da vida na exceção soberana, a testemunha e sua linguagem:(re) leituras biopolíticas da obra de Giorgio Agamben. UNISINOS: Instituto Humanitas, 2012. Disponível em: http://www.ihu.unisinos.br/images/stories/cadernos/ihu/039cadernosihu.pdf Acesso em: 15 jan. 2021.

SIQUEIRA, Dirceu Pereira; CASTRO, Lorenna Roberta Barbosa. Minorias e grupos vulneráveis: a questão terminológica como fator preponderante para uma real inclusão social. In: Revista direitos sociais e políticas públicas (UNIFAFIBE). v.5, n.1, 2017. Disponível em: <http://www.unifafibe.com.br/revista/index.php/direitos-sociais-politicaspub/article/view/219/pdf>. Acesso em: 29 jan. 2021.

SOARES, Marcelo Negri; KAUFFMAN, Marcos Eduardo; CHAO, Kuo-Ming. Inteligência Artificial: Impactos no Direito e na Advocacia. Revista de Direito Público - RDP, Brasília, v. 17, n. 93, p. 104-133, maio/jun. 2020.

SOUZA, Danigui Renigui Martins de. A biopolítica em Giorgio Agamben: Estado de exceção, poder soberano, vida nua e campo. Dissertação de Mestrado. UFRN, 2017.

TOMASEVICIUS FILHO, E. Artificial intelligence and personality rights; Inteligência artificial e direitos da personalidade. [s. l.], 2018. DOI 
10.11606/issn.2318-8235.v113i0p133-149. Disponível em: $<$ https://search.ebscohost.com/login.aspx?direct=true\&db=edsbas\&AN=edsbas. 98 6208EE\&lang=pt-br\&site=eds-live>. Acesso em: 29 de jan. 2020.

UNESCO. Outcome document: first version of a draft text of a recommendation on the Ethics of Artificial Intelligence, 2020. Disponível em: https://unesdoc.unesco.org/ark:/48223/pf0000373434 Acesso em: 30 jan. 2021.

VALENCIA, Sayak. Capitalismo Gore. España: Melusina, 2010.

WERMUTH, Maiquel Ângelo Dezordi; MARCHT, Laura Mallmann; Mello, Letícia de. Necropolítica: racismo e políticas de morte no Brasil contemporâneo. Revista de Direito da Cidade, Rio de Janeiro, vol. 12, n. 2, p. 122-152, 2020.

WOLOWSKI, Matheus Ribeiro de Oliveira; CARDIN, Valéria Silva Galdino. A tutela normativa dos direitos da personalidade frente aos avanços da Inteligência Artificial. Revista de Direito, Governança e Novas Tecnologias. v.6, n. 2, p. 4364, 2020. Disponível em:

$<$ https://indexlaw.org/index.php/revistadgnt/article/view/7002/pdf $>$. Acesso em 02 fev. 2021.

ZMOGINSKI, Felipe. Sem acidentes graves, China libera 5.000 caminhões autônomos nas estradas. Canal sobre tecnologia do UOL. 03/02/2021. Disponível em: <https://www.uol.com.br/tilt/colunas/felipe-zmoginski/2021/02/03/empresachinesa-estreia-frota-de-5-mil-caminhoes-autonomos.htm>. Acesso em: 04 fev. 2021. 